\title{
SLIKA ŽENE U ROMANU NESSUNO TORNA INDIETRO ALBE DE SESPEDES
}

Cilj ovog rada jeste osvijetliti neke od aspekata stvaralaštva italijansko-kubanske književnice i intelektualke Albe de Sespedes kroz Nessuno torna indietro (Nikome nema povratka, 1938), roman kojim je autorka ostvarila prvi zapažen korak u karijeri. U djelu se prepliću priče o osam studentica smještenih u jednom rimskom internatu tridesetih godina XX vijeka. Nakon kratkog osvrta na okolnosti u kojima je nastao roman, te na njegovu recepciju, u radu ćemo se kroz analizu lika Silvije fokusirati na sliku žene daleke od modela nametnutog od strane fašističkog režima. Ideja Albe de Sespedes da na ovaj način prikaže svoje junakinje simbolično ukazuje na autorkino neslaganje sa položajem i ulogom koje je ženi dodijelila Musolinijeva diktatura.

Ključne riječi: Alba de Sespedes, Nessuno torna indietro, roman, italijanska književnost XX vijeka, fašizam, položaj žene.

\section{UVOD}

Alba de Sespedes (Alba de Céspedes, 1911-1997), italijansko-kubanska književnica, ${ }^{1}$ novinarka i angažovana intelektualka, aktivna u periodu od tridesetih do početka osamdesetih godina XX vijeka, pripada drugoj generaciji italijanskih autorki XX vijeka, koje stupaju na književnu scenu u periodu između dva rata, a

*zorana.kovacevic@flf.unibl.org

${ }^{1}$ Alba de Sespedes je rođena u Rimu, od majke Italijanke i oca diplomate kubanskog porijekla. Djed Albe de Sespedes, Karlos Manuel de Sespedes i del Kastiljo (Carlos Manuel de Céspedes y del Castillo), bio je revolucionar i predsjednik Republike Kube, poznat u narodu kao „otac nacije”. Alba de Sespedes je često isticala vezanost za očevu zemlju, o kojoj, između ostalog, svjedoči odlomak iz posljednjeg, nedovršenog romana, Con grande amore, posvećenog upravo Kubi: ,[...] Italija je zemlja u kojoj sam rođena [...]... Ali Kuba, Kuba je moja domovina [...], učinila bih bilo šta za Italiju, Francuskoj ću zauvijek biti zahvalna, ali samo za Kubu - za ono što je danas Kuba - bih bila spremna umrijeti” (De Céspedes, 2011: 1592). Svi prevodi citata sa italijanskog na srpski jezik su moji. 
stasavaju i afirmišu se nakon pada fašističkog režima. Uprkos činjenici da je svojim aktivnostima dala značajan doprinos društvu i kulturi za vrijeme i neposredno po završetku Drugog svjetskog rata, ${ }^{2}$ Alba de Sespedes je nepravedno bila zapostavljena u kritičkoj i čitalačkoj recepciji do kraja prošlog vijeka, kada nas je kako na vrijednost njenih književnih ostvarenja tako i na autorkin angažman na kulturnom i društvenom polju na prvom mjestu podsjetila Marina Cankan (Marina Zancan), autorka istaknutih studija iz oblasti ženske književnosti. ${ }^{3}$

Od kraja devedesetih godina prošlog vijeka pa sve do danas nizali su se različiti povodi za studije o Albi de Sespedes, koji su rezultirali objavljivanjem velikog broja radova, zbornika i monografija, napisanih iz pera italijanskih, ali i drugih evropskih i neevropskih stručnjaka. Bez obzira na činjenicu da je djelo ove spisateljice imalo velikog odjeka van granica Italije, prvenstveno zahvaljujući prevodima njenih romana, ono je ostalo skoro nepoznato na tlu bivše Jugoslavije, ali i na području Balkana. Raznorodan i bogat opus Albe de Sespedes samo je djelimično predstavljen čitalačkoj publici na srpskom i hrvatskom govornom području, i to preko prevoda triju romana: Nessuno torna indietro (Nikome nema povratka, 1938), Dalla parte di lei (Na njenoj strani, 1949) i Quaderno proibito (Zabranjena sveska, 1952), koji su objavljivani u periodu od 1941. do 1980. godine. Nema sumnje da je prestanak štampanja ovih djela, zajedno sa manjkom interesa za prevođenje ostatka opusa ove književnice, negativno uticao na njenu recepciju i uspjeh na tlu bivše Jugoslavije. Stoga je jasno da bi današnji čitalac sa srpskog i

${ }^{2}$ Ovaj period se zasigurno može smatrati najintenzivnijim i najplodnijim u životu i karijeri Albe de Sespedes. Književnica je za vrijeme okupacije sarađivala sa antifašističkim radiom u Bariju i Napulju, a nakon rata uređivala je časopis „Mercurio” (1944-1948), oko kojeg su se okupila istaknuta imena literarnog i kulturnog miljea tog perioda. Riječ je o jednom i te kako uspjelom projektu i važnom doprinosu društveno-kulturnom životu poslijeratnog Rima - grada koji je u to vrijeme prednjačio po broju intelektualaca. Uz privrednu obnovu zemlje nakon rata išla je naporedo i korjenita promjena italijanskog društveno-kulturnog života, predvođena tim istim intelektualcima koji su, baš kao i sama Alba de Sespedes, imali namjeru da, između ostalog, putem osnivanja časopisa, ali i kroz niz drugih aktivnosti, edukuju populaciju. Za više detalja o pomenutom časopisu i aktivnostima književnice za vrijeme pokreta otpora upućujem na istraživanja Laure di Nikole (Di Nicola, 2012 i 2013b), Lučije de Krešencio (De Crescenzio, 2015) i Valerije P. Babini (Babini, 2018).

${ }^{3}$ Godine 2001. Marina Cankan, uz nesebičnu pomoć svojih saradnica, objavljuje prvu značajnu publikaciju posvećenu književnici - Scrittrici e intellettuali del Novecento. 2. Alba de Céspedes. Četiri godine kasnije priređuje zbornik radova kojim su obuhvaćeni skoro svi aspekti plodnog stvaralaštva italijansko-kubanske književnice (Zancan, 2005). 
hrvatskog govornog područja koji se ne služi italijanskim jezikom naišao na niz poteškoća u slučaju da se odluči upoznati sa stvaralaštvom Albe de Sespedes.

Istraživanje sprovedeno u ovom radu, usredsređeno na mladalački roman Nessuno torna indietro, koji je doživio slavu svjetskih razmjera, ali i izazvao niz oprečnih reakcija i mišljenja, ima za cilj da osvijetli neke od aspekata autorkinog stvaralaštva, te da podstakne istraživače da nastave studije u ovom pravcu. Nakon kratkog osvrta na okolnosti u kojima je nastalo djelo, te na njegovu recepciju, u radu ćemo se kroz analizu lika Silvije fokusirati na sliku žene, daleke od modela nametnutog od strane fašističkog režima. Ideja Albe de Sespedes da na ovaj način prikaže svoje junakinje simbolično ukazuje na autorkino neslaganje sa položajem i ulogom koje je ženi dodijelila Musolinijeva diktatura.

\section{NESSUNO TORNA INDIETRO: IZMEĐU USPJEHA I FAŠISTIČKE CENZURE}

Godine 1938, kada izdavačka kuća Mondadori objavljuje roman Nessuno torna indietro, opus Albe de Sespedes broji nekoliko književnih ostvarenja: zbirke pripovjedaka L'anima degli altri (Duša drugih, 1935) i Concerto (Koncert, 1937), poetsku zbirku Prigionie (Tamnovanja, 1936), te kratki roman Io, suo padre (Ja, njegov otac, 1935). U punom zamahu fašizma, kada je afirmacija žena na književnom polju često bila teška i mukotrpna, kako podvlači i sama Alba de Sespedes (Carroli, 1993: 135), mlada književnica, već nakon objavljivanja prve pripovijetke, Il dubbio (Sumnja, 1934), shvata da je pisanje aktivnost bez koje ne može zamisliti život, što će mnogo godina kasnije potvrditi u jednom intervjuu: „Mislim da se ideja o pisanju rodila zajedno sa mnom. [...] Ja, u stvari, nisam nikada donijela odluku da pišem, oduvijek sam pisala. Ne mogu da zamislim svoj život bez pisanja jer za mene nikada nije postojao takav život" (Carroli, 1993: 190191). ${ }^{4}$ Iako nije prvo djelo napisano iz pera Albe de Sespedes, roman Nessuno torna indietro po mnogo čemu može se smatrati njenim prvencem. Nakon eksperimentisanja sa književnim žanrovima i formama, kojim su obilježeni početni koraci u karijeri ove autorke, Nessuno torna indietro simbolično ukazuje na odabir

\footnotetext{
${ }^{4} \mathrm{O}$ ulozi i značaju pisanja u životu ove spisateljice osim književnih djela svjedoče i bogata prepiska sa prevodiocima, izdavačima i drugim intelektualcima, dnevnici, novinarski članci, te tekstovi sa društveno-političkom pozadinom. Pisanje se nameće kao apsolutna potreba i za vrijeme boravka u Abrucu, kada Alba de Sespedes, uprkos poteškoćama i strahu od okupatora, ne odustaje od vođenja dnevnika (De Crescenzio, 2015: 37-52).
} 
romana kome će književnica ostati vjerna do kraja života. Osim toga, neke od tema aktuelizovanih u romanu spisateljica će oživjeti i u narednim djelima - na prvom mjestu interesovanje za položaj žene u društvu.

Radnja Nessuno torna indietro odvija se u Rimu, u periodu od 1934. do 1936. godine. U ovom romanu o odrastanju prepliću se priče o osam mladih žena, uglavnom studentica književnosti, međusobno različitih, kako po porijeklu i društvenom statusu tako i po karakternim osobinama i životnim ciljevima. Neke od tipologija ženskih likova koje su obilježile ovo djelo evoluiraće u kasnijim romanima Albe de Sespedes..$^{5}$ Boravak u ženskom internatu „Grimaldi”, u kom junakinje odsjedaju za vrijeme studija, sve one doživljavaju kao prelaznu fazu između bezbrižne mladosti i svijeta odraslih, pa će stoga Silvija opisati „Grimaldi” kao most:

Čini se kao da se nalazimo na mostu. Pošle smo sa jedne obale, a nismo još stigle na drugu. Obala koju smo ostavile je iza nas, a mi se čak ne osvrćemo da je pogledamo. Ona koja nas čeka je još uvijek obavijena maglom, te ne znamo uopšte šta ćemo otkriti kada se magla povuče. Neke od nas se previše nagnu da bi bolje vidjele rijeku, padnu i utope se. Druge, umorne, sjednu na zemlju i ostanu na mostu. Ostale, neke ovako, neke onako, uspiju da ga pređu i stignu do druge obale (De Céspedes, 2011: 76) .

Recepcija Nessuno torna indietro od strane čitalaca i kritike jasno je ukazivala na činjenicu da je književnica ovim djelom ostvarila prvi zapažen korak u karijeri. O razlozima uspjeha svog romana Alba de Sespedes progovara u više navrata, a, između ostalog, u već pomenutom intervjuu naglašava da su raznolikost ženskih sudbina i realistični pristup likovima zasigurno doprinijeli popularnosti: „Prije svega jer se radi o priči o ženama koja je, kako se čini, bila dobro ispričana. U tom periodu postojao je veliki broj knjiga koje su bile daleke od realnosti" (Carroli, 1993: 182).

\footnotetext{
${ }^{5}$ Za više detalja o evoluciji ženskog lika u romanima ove spisateljice upućujem na rad Marije Rozarije Viti-Aleksander (Vitti-Alexander, 1991).

${ }^{6}$ Hrvatski prevod romana iz pera Ante Velzeka, naslovljen Nikome nema povratka, ugledao je svjetlost dana 1941. godine. S obzirom na to da smo se pri citiranju oslanjali na posljednje izdanje romana, odlučili smo da ponudimo svoj prevod odlomaka, jer je Velzekov prevod sačinjen prema izdanju iz 1938. godine.
} 
Odmah po objavljivanju počeli su se nizati i prvi prikazi: na stranicama časopisa i dnevnih listova neka od najznačajnijih imena ondašnje kulture, među kojima je veliki broj uglednih kritičara i afirmisanih pisaca, podržavaju i uveliko hvale roman. ${ }^{7}$ Kako tvrdi sama Alba de Sespedes, u avgustu 1939. godine uspjeh Nessuno torna indietro trebalo je da bude okrunjen prestižnom nagradom Viareggio, ali književnica je ostala uskraćena za priznanje zbog naredbe koja je žiriju stigla direktno iz Rima (Zancan, 2011: 1618). Godine 1966, u ediciji „Narratori italiani” izdavačke kuće Mondadori, izlazi posljednja izmijenjena verzija romana. Ako se uporedi prvo izdanje romana, iz 1938, sa izdanjem iz 1966. godine, uočava se da je spisateljica izvršila veliki broj izmjena, prevashodno jezičke i stilističke prirode - jasan pokazatelj njenog književnog sazrijevanja. Sa uspjehom u Italiji naporedo je išla i slava u inostranstvu: nakon što je prvi prevod romana na mađarski jezik ugledao svjetlost dana, već 1939. godine, slijede prevodi na osamnaest jezika, objavljivani u kontinuitetu do 2003. godine, u više od dvadeset evropskih i vanevropskih zemalja. ${ }^{8}$

Iako je priča o osam studentica doživjela devetnaest izdanja već u decembru 1940. godine, mjesec dana kasnije, početkom 1941. godine, na stranicama časopisa „Vita italiana” Pjero Pelikano (Piero Pellicano) oštro je osudio roman. Razlozi osude su moralno-politički, a na meti kritike našle su se prevashodno dvije junakinje i njihovi postupci: Ksenijin životni odabir i Emanuelina vizija porodice i majčinstva, koja se, prema riječima kritičara, kosi u potpunosti sa fašističkom etikom. Nakon objavljivanja Pelikanijevog članka, izdavačkoj kući Mondadori naređeno je da prestane sa štampanjem novih izdanja romana i otkaže sve pregovore u vezi sa prevodima. Smatra se i da je pravi povod za ovakve reakcije bio početak dogovora o snimanju filma koji bi se bazirao na romanu Nessuno torna indietro (Bonsaver, 2013: 154-155). Uprkos činjenici da se Alba de Sespedes branila i pokušavala da svoje djelo predstavi u potpuno drugačijem svjetlu, situacija se pogoršala nakon nekoliko mjeseci, kada je dodatno optužena da je njen dom utočište antifašista. ${ }^{9}$ Osude koje su se nizale i konstantne

${ }^{7} \mathrm{Za}$ više detalja o recepciji romana od strane italijanske kritike upućujem na tekst Marine Cankan (Zancan, 2011).

${ }^{8} \mathrm{Za}$ više podataka o recepciji i prevodima djela Albe de Sespedes u inostranstvu upućujem na rad Laure di Nikole (Di Nicola, 2013a).

${ }^{9}$ Problemi Albe de Sespedes sa režimom nisu bili samo književne prirode, te datiraju još iz 1935. godine, kada je spisateljica, optužena za telefonski razgovor sumnjivog sadržaja, provela nekoliko dana u zatvoru. O kompleksnom i konfliktnom odnosu Albe de Sespedes 
presije navele su književnicu da traži susret sa Dučeom, koji nikada nije bio realizovan, ali i zaštitu Alesandra Pavolinija (Alessandro Pavolini), tadašnjeg ministra kulture. Iako su se na kraju reakcije stišale, te je Musolini odobrio snimanje pomenutog filma ${ }^{10}$, nakon što je Alba de Sespedes pristala da prilagodi scenario zahtjevima Ministarstva popularne kulture ${ }^{11}$, odnosi sa režimom ostali su napeti sve do njegovog pada.

\section{INTELEKTUALKA U ERI FAŠIZMA}

Sa ciljem da uspostavi potpunu kontrolu u svim sferama društva, fašizam je, između ostalog, dao sebi zadatak da oblikuje novi tip Italijana, sa drugačijim vrijednostima i oblicima ponašanja. Stoga ,novi čovjek, modelovan u omladinskim organizacijama i pomoću partijske propagande, trebalo je da bude ratnik muževan, patriota, disciplinovan i strog” (Dagan, 2013: 196), a „nova žena” prije svega odana supruga i dobra majka, „kraljica ognjišta” (Vitti-Alexander, 1991: 103). Najbolji način da žena izrazi svoju odanost i korist državi i Dučeu jeste bio da na svijet donese što veći broj potomaka, jer je, po Musoliniju, snaga nacije počivala upravo na njenoj brojnosti. Godine 1927. zvanično je pokrenuta demografska kampanja - svojevrsna mješavina propagande i finansijskih podsticaja, čiji je cilj bio podizanje nataliteta, ali i kontrola stope smrtnosti i odliva stanovništva. Velike porodice nerijetko su bile oslobađane plaćanja poreza, bogato nagrađivane i primane kod Dučea, a neženje sankcionisane plaćanjem takse (De Grazia Luzzatto, 2002: 225-229).

Dok je posao muškarcima bio nezamisliv za izgradnju njihovog identiteta, prema Musolinijevim riječima, postojala je opasnost da upravo zbog rada žene skrenu sa pravog puta, koji je nužno vodio ka ispunjenju dužnosti prema naciji, $\mathrm{tj}$. rađanju djece: ,posao udaljava žene od začeća, podstiče nezavisnost i ponašanje koje se ne uklapa u ideje o rađanju" (De Grazia, 1996: 163). Moderne i emancipovane žene doživljavane su kao prijetnja, a fašistička propaganda na sve

sa fašizmom svjedoči i odlomak iz intervjua Sandre Petrinjani sa autorkom: „Za vrijeme fašizma su me snašle mnoge nevolje. Sve moje je bilo zabranjeno" (Petrignani, 1996: 40).

${ }^{10} \mathrm{Za}$ više detalja o filmu Nessuno torna indietro upućujem na radove Lučije Kardone (Cardone, 2012) i Glorije Monti (Monti, 2008).

11 Ministarstvo popularne kulture (Ministero della cultura popolare) osnovano je 1937. godine, sa ciljem sprovođenja kontrole nad medijima i štampom, kao i pojačavanja političke propagande (De Grazia - Luzzatto, 2003: 132-135). 
načine pokušavala je da nametne sliku žene-majke, ruralne, plodne i stamene, kojoj se suprotstavljala urbana žena - dekadentna i sterilna. Antifeministički stavovi bili su dio fašističkih vjerovanja isto kao $i$ antiliberalizam, rasizam i militarizam. ${ }^{12}$ Stoga je jasno da je u ovakvim društvenim okolnostima figura intelektualke bila zasigurno osporavana i teško prihvatana. Neslaganje Albe de Sespedes sa fašističkom vizijom žene očituje se u odabiru intelektualke kao ključne figure romana Nessuno torna indietro. Kroz lik Silvije književnica prikazuje pozitivnu stranu odnosa između ženskog identiteta i intelektualnog rada, te pokazuje da je tridesetih godina prošlog vijeka postojala mogućnost da, uprkos svim poteškoćama, žene izađu iz okova nametnutih od strane društva i ostvare svoje ambicije.

Zajedno sa Avgustom, koja vrijeme provodi pišući uzaludno romane, Silvija čini intelektualni ogranak grupe od osam djevojaka. Porijeklom iz Kalabrije, iz skromne i mnogočlane porodice, ova junakinja je uspješna studentica književnosti, svjesna kompleksnog procesa „prelaska mosta”, te jedina od svih djevojaka koja od početka romana ima jasno zacrtane ciljeve: ,[...] iskreno vjerujem da je ključno u životu odabrati put i slijediti ga do kraja [...]" (De Céspedes, 2011: 75). Pomalo neugledna i u potpunosti posvećena učenju, Silvija je prototip žene daleke od fašističkih ideala, s obzirom na to da ne utjelovljuje potencijalnu idealnu majku i suprugu. U vrijeme kada su mnogočlane porodice hvaljene i nagrađivane, Silvija ne krije svoju ravnodušnost prema braku: „Ja se nikada neću udati” (De Cespedes, 2011: 18). Uspjeh na univerzitetu u ovoj junakinji dodatno izaziva nezainteresovanost za ljubav, za razliku od većine djevojaka iz Grimaldija i njenih sestara, koje su od djetinjstva maštale o braku.

Zbog neobičnih interesovanja za okruženje u kome je odrastala, želje za nezavisnošću i nezanimanja za tipične ,ženske poslove", ${ }^{13}$ Silvijina ženstvenost je dovedena u pitanje već u krugu porodice, kada postaje jasno da se u potpunosti razlikuje od svojih sestara: „Zar niste vidjeli Silviju u bratovim hlačama? Pa i ona je muškarac" (De Céspedes, 2011: 114). Model žene koji Silvija utjelovljuje relativno je nov za doba u kojem živi, pa je stoga ostali likovi u knjizi doživljavaju kao drugačiju i blisku muškom polu. U jednom od brojnih razgovora o ljubavi, omiljenoj temi djevojaka iz Grimaldija, Vinka ističe Silvijinu različitost, te

12 Za više detalja o položaju i ulozi žene za vrijeme fašističkog režima upućujem na monografiju Vitorije de Gracije (De Grazia, 2007).

13 „Ujutru je oblačila hlače starijeg brata i jahala uz kanal; a potom, nakon što bi privezala konja, lijegala bi na livadu da čita ili da razmišlja" (De Céspedes, 2011: 114). 
naglašava da je njena ženstvenost isključivo umna i potpuno odvojena od tjelesne sfere: „Radom pokušavaš da nadomjestiš ljubav. Kada si došla da nam kažeš da si počela raditi sa Belucijem trebalo je da vidiš svoj izraz lica..." (De Céspedes, 2011: 74).

Silvija je bliža muškom nego ženskom polu takođe u očima profesora Belucija, koji preferira ,,prave žene”, poput njegove supruge Dore - naizgled odane, daleke od akademskog svijeta i intelektualnih aspiracija. U jednom od dijaloga između Silvije i profesora, Beluci, osim što podvlači razliku između Silvije i Dore, čiju pojavu upoređuje sa daškom svježeg vazduha, ne krije svoj stav da su žene koje se bave intelektualnim radom lišene ženstvenosti, podržavajući na ovaj način tipični fašistički stereotip:

Dora je potpuno drugačija od nas. Sviđaju joj se ljudi, pokret... Dora je tako puna života, ona je prava žena, eto, baš prava žena... Šta drugo reći? U njenom prisustvu ne mogu pričati o mom poslu i to me zaista odmara. Mi koji smo stalno obuzeti mislima treba da pored sebe imamo osobu koja uopšte ne razmišlja, jer bismo se u protivnom ugušili. Kada naveče zajedno večeramo, imam osjećaj da udišem svjež vazduh pored otvorenog prozora (De Céspedes, 2011: 113).

Upravo je susret sa profesorom ključan, ne samo za Silvijino intelektualno sazrijevanje već i za sagledavanje odnosa između intelektualnog rada i ženskog identiteta. Beluci je na početku knjige jedini Silvijin model i uzor, ali i spona sa akademskim svijetom, u kome su tridesetih godina prošlog vijeka dominirale muške figure. Početno divljenje profesorovom naučnom radu pretvara se $u$ jedan nedefinisan osjećaj, blizak ljubavnom. Međutim, s druge strane, čest odlazak u Belucijev dom radi zajedničkog rada i susreti sa Dorom nude Silviji mogućnost da bude u bliskom kontaktu sa rimskim građanskim miljeom i otkrije njegovo naličje. Iscenirani pokušaj Dorinog samoubistva nakon što je ljubavnik ostavlja, te činjenica da Beluci zbog djeteta koje čeka želi da se povuče iz akademskog svijeta, između ostalog, razlozi su Silvijinog udaljavanja od profesora i prevazilaženja prvobitnog modela koji je vidjela u njemu. Osjećanja koja je Silvija gajila prema Beluciju prerastaju u neku vrstu prezira i sažaljenja, ne samo zbog toga što profesor prećutno prelazi preko činjenice da dijete koje nosi Dora možda nije njegovo, već ponajviše što zbog dolaska prinove razmišlja da napusti posao na univerzitetu, odričući se na taj način svojih životnih ciljeva i interesovanja. Stoga Silvija pomišlja da profesor „možda nikada nije istinski vjerovao u posao, u književnost, pa čak ni u ljubav” (De Céspedes, 2011: 253).

Poznanstvo sa Belucijevom suprugom pomoći će Silviji da spozna razliku između istinske ljubavi i lažnih osjećanja. Dorinom liku je snažno suprotstavljena 
Vinka, djevojka iz Španije koja je zaljubljena u svog sunarodnika Luisa. Zahvaljujući Vinkinoj neizmjernoj ljubavi, Silvija prestaje da gleda na ovo osjećanje kao na slabost i znak egoizma, i počinje da ga doživljava kao simbol snage: ,[...] smijem se kada čujem ovu riječ, oduvijek sam je smatrala slabošću; ali kada vidim Vinku pomislim da ljubav zaista postoji i da je njena snaga velika" (De Céspedes, 1938: 282). Ovo priznanje je jasan pokazatelj Silvijinog sazrijevanja i napretka, na kome spisateljica vidno insistira u završnom dijelu romana. Međutim, presudni korak koji vodi ka Silvijinoj evoluciji i konačnoj samospoznaji nazire se iz pisma koje ova junakinja šalje iz Litorije djevojkama u Grimaldiju. ${ }^{14}$ Boravak u novom okruženju doprinosi da Silvija pored umne postane svjesna i tjelesne dimenzije, o čemu svjedoči njeno opažanje da je predmet pogleda drugih (,posmatrali su me”). Osim toga, insistiranje na prisvojnim zamjenicama u prvom licu jednine (,moja katedra”, „,moj glas”, „moje ideje”), umjesto zamjenica u prvom licu množine, koje je Silvija upotrebljavala ranije da bi ukazala na kolektivno iskustvo, simbolično nagovještava proces individualizacije, koji je junakinja uveliko započela. Silvija uspješno ,prelazi most”, ostvaruje svoje ciljeve, te sazrijeva po pitanju odnosa prema sopstvenoj ženstvenosti.

\section{MEĐU USAMLJENIM ŽENAMA}

Kroz lik Silvije Alba de Sespedes prikazala je ženu intelektualku, koja uprkos društvenim barijerama uspijeva da se izbori za svoj položaj u društvu tridesetih godina prošlog vijeka. Iako drugi njenu intelektualnu superiornost vide kao anomaliju, u Silvijinom slučaju vjera u sopstvene sposobnosti i želja za postizanjem ciljeva pobjeđuju. Silvija simbolično započinje proces emancipacije, koji će nastaviti i upotpuniti Mirela iz romana Quaderno proibito (1952) i Irene iz Prima e dopo (Prije i poslije, 1955). Upravo ova činjenica potvrđuje da, osim za Nessuno torna indietro, Silvijin lik ima i te kako važnu ulogu u cjelokupnom stvaralaštvu italijansko-kubanske književnice.

Silvija je simbol otpora prema jasno prepoznatljivom sistemu vladanja ženama, koji je izgradila Musolinijeva diktatura. Da je književnica vješto

${ }^{14} \mathrm{U}$ izdanju iz 1966. godine spisateljica je unijela nekoliko promjena u vezi sa Silvijinim likom. Tako je, na primjer, posao u gimnaziji u Litoriji zamijenjen katedrom u Pizi. Iako smo se u radu oslanjali na posljednje izdanje romana, odlučili smo da se u paragrafu koji se tiče Silvijine evolucije pozovemo na izdanje iz 1938. godine, s obzirom na to da je u njemu jasnije ilustrovan ovaj proces. 
oblikovala likove koji se ne podudaraju sa slikom žene propagiranom od strane režima potvrđuju i priče o ostalim junakinjama romana, od kojih se posebno izdvaja Emanuela. Konačan bijeg od komplikovane prošlosti i mogućnost otpočinjanja novog života nude se Emanueli nakon što se upusti u ljubavnu vezu sa kolegom sa univerziteta. Međutim, nimalo slučajno, roman simbolično zatvara njena odluka da krene na dugo putovanje, odbije tradicionalnu ulogu supruge i majke, te odabere alternativni životni put, pun neizvjesnosti. Dok se sa kćerkom nalazi na brodu Amazonia, u kozmopolitskom okruženju, gdje joj ,niko nije upućivao pitanja u vezi sa njenim privatnim životom" (De Céspedes, 2011: 301), Emanuela odbacuje ideju da bi jednog dana mogla biti Andreina supruga, zarobljena u malograđanskom braku: „Ostarila bi pored njega, među trgovcima i malograđanima: naveče kino, poslije pica, a ljeti Rimini i Ričone. Na ovu pomisao bi joj prolazili trnci niz kičmu” (De Céspedes, 2011: 297). Upravo činjenica da se samo jedna junakinja Nessuno torna indietro opredjeljuje za brak ukazuje na to da je u djelu doveden u pitanje odabir tradicionalnog životnog puta, te da je tridesetih godina prošlog vijeka postojala potreba za korjenitom promjenom po pitanju odnosa među polovima i za afirmacijom žena izvan porodičnih okvira.

\section{Zorana Kovačević}

THE IMAGE OF A WOMAN IN ALBA DE CÉSPEDES' NOVEL NESSUNO TORNA INDIETRO

\section{Summary}

The paper is the result of a literary study focused on the Italian-Cuban writer and journalist Alba de Céspedes' novel Nessuno torna indietro (There's No Turning Back, 1938), which chronicles different stories of eight women students residing in a boarding house (Grimald in Rome) between 1934 and 1936. It is with this work that Alba de Céspedes, one of the most important figures in the Italian literary and cultural ambit in the post-war period, made the first important step in entering the literary scene. The book, which focuses on the condition of women as a topic that takes center stage in de Céspedes' writing, was immensely popular and saw translations into eighteen languages worldwide, but it also became the subject of censorship. In this paper, after preliminary considerations dealing with the genesis of the novel and its reception in Italy and abroad, we will examine the character of Silvia, which stands in sharp contrast to the Fascist model of a woman as an exemplary wife and mother. This way of portraying the protagonists of Nessuno torna indietro shows the writer's disagreement with the accepted view, the status of women, and rules promoted by the Fascist ideology. Another purpose of this paper is to introduce the 
writer's work and cultural practice to the Balkan region and offer a basis for further discussion on the subject.

Key words: Alba de Céspedes, Nessuno torna indietro, novel, $20^{\text {th }}$-century Italian literature, Fascism, position of women.

\section{LITERATURA}

Babini, P. V. (2018). Parole armate. Le grandi scrittrici del Novecento italiano tra Resistenza ed emancipazione. Milano: La Tartaruga.

Bonsaver, G. (2013). Mussolini censore. Storie di letteratura, dissenso e ipocrisia. Bari: Laterza.

Cardone, L. (2012). Pelle e pellicola. La scrittura femminile e lo sguardo in Nessuno torna indietro di Alba de Céspedes e Alessandro Blasetti. In: Chemotti, S. (a cura di) (2012). Le graphie della cicogna. La scrittura delle donne come ri-velazione. Padova: Il Poligrafo. 289-332.

Carroli, P. (1993). Esperienza e narrazione nella scrittura di Alba de Céspedes. Ravenna: Longo Editore.

Dagan, K. (2013). Kratka istorija Italije. Beograd: Zavod za udžbenike.

De Céspedes, A. (1938). Nessuno torna indietro. Milano: Mondadori.

De Céspedes, A. (1941a). Nikome nema povratka, I dio. Preveo A. Velzek. Zagreb: Nakladni zavod Ante Velzek.

De Céspedes, A. (1941b). Nikome nema povratka, II dio. Preveo A. Velzek. Zagreb: Nakladni zavod Ante Velzek.

De Céspedes, A. (2011). Romanzi. Milano: Mondadori.

De Crescenzio, L. (2015). La necessità della scrittura. Alba de Céspedes tra Radio Bari e «Mercurio» (1943-1948). Bari: Stilo.

De Grazia, V. (1996). Il patriarcato fascista: come Mussolini governò le donne italiane (1922-1940). In: Thébaud, F. (a cura di) (1996). Storia delle donne. Il Novecento. Bari: Laterza. 141-175.

De Grazia, V., Luzzatto, S. (a cura di) (2002). Dizionario del fascismo I. A-K. Torino: Einaudi.

De Grazia, V., Luzzatto, S. (a cura di) (2003). Dizionario del fascismo II. L-Z. Torino: Einaudi.

De Grazia, V. (2007). Le donne nel regime fascista. Venezia: Marsilio.

Di Nicola, L. (2012). Intellettuali italiane del Novecento. Una storia discontinua. Pisa: Pacini Editore.

Di Nicola, L. (2013a). Il canone inverso. I classici italiani del Novecento all'estero. In: Di Nicola, L., Schwartz, C. (a cura di) (2013a). Libri in viaggio. 
Classici italiani in Svezia. Stoccolma: Acta Universitatis Stockholmiensis. 64-88.

Di Nicola, L. (2013b). Mercurio. Storia di una rivista 1944-1948. Milano: Il Saggiatore.

Monti, G. (2008). Look Who's Talking: Nessuno torna indietro, From Alba de Céspedes to Alessandro Blasetti. In: De Pau, D., Torello, G. (a cura di) (2008). Watching Pages, Reading Pictures: Cinema and Modern Literature in Italy. Cambridge: Cambridge Scholars P. 191-211.

Pellicano, P. (gennaio 1941). Potenze occulte. Vita italiana. pp. 83-85.

Petrignani, S. (1984). Alba de Céspedes. La Pasionaria. Le signore della scrittura. Milano: La tartaruga.

Vitti-Alexander, M. R. (1991). Il passaggio del ponte: l'evoluzione del personaggio femminile di Alba de Céspedes. Campi immaginabili, 3, 103-112.

Zancan, M. (a cura di) (2001). Scrittrici e intellettuali del Novecento. 2. Alba de Céspedes. Milano: Fondazione Arnoldo e Alberto Mondadori.

Zancan, M. (a cura di) (2005). Alba de Céspedes. Milano: Il Saggiatore, Fondazione Arnoldo e Alberto Mondadori.

Zancan, M. (2011). Nessuno torna indietro. In: De Céspedes, A. (2011). Romanzi. Milano: Mondadori. 1611-1629. 